\title{
Effects of Phthalates on Animal Health
}

\author{
Beyza Aydogan \\ Afyon Kocatepe University, Faculty of Veterinary Medicine, \\ Department of Biochemistry, Afyonkarahisar, Turkey \\ E-mail: byzaaydoan@gmail.com \\ A. Fatih Fidan \\ Afyon Kocatepe University, Faculty of Veterinary Medicine, \\ Department of Biochemistry, Afyonkarahisar, Turkey \\ E-mail: ffidan@aku.edu.tr
}

\begin{abstract}
In daily life plastics are used widely due to their easy-to-use characteristics and low cost advantages. Some additives used in the contents of these plastics present more risk compared others. Especially, the plasticizers which soften and add elasticity to plastics form the highest risk. Phthalates, as plasticizers, are the most commonly used compounds used in sectors like food packaging, toys, make-up products, medical instruments, textiles and construction materials. Phthalates, which used commonly in daily life, are not only chemically harmful; additionally they endanger the biologic system and also the health of all living creatures and organisms. These compounds are organic contaminants, they do not dissolve in water but dissolve in oil, they do not tie up with covalent bond to plastics. Thus they can easily spread to the environment through the multipath such as water, air and others. These phthalates which are inimical to health and nature, cause adverse effect on animals as well. One of the most commonly used phthalates di-(2-ethylhekzyl) DEHP causes liver, kidney and lung problems in animals when they are exposed to this compound, additionally it was found out that the reproduction systems of animals may be negatively affected, especially those that are exposed to phthalates during the postnatal period. Phthalates used in wide range of industrial scopes are among the chemicals materials that are carcinogenic, and they negatively affect hormonal metabolism. This paper discusses the negative effects of the highly toxic phthalates on animal health.
\end{abstract}

Keywords: Phthalates, Animal health, Plasticizers

DOI: $10.7176 / \mathrm{JSTR} / 7-09-01$

\section{Introduction}

Since years 1902, after the first synthetic material was produced in full measure by Polymer Science or macromolecular science, plastics have improved and development and widespread use of plastics have been very swift (Vural, 1977). Plastics improved, became superior to other materials due to their composition and started to be commonly used in all aspects of our lives, industry and medicine. Their widespread use in our daily lives due to the richness of their characteristics and variety, plastics are also economically significant (Hüner, 2008). Plastics are lighter in weight and can be reshaped with heat, when cooled stay as a hard mould, and with such benefits they can be widely used in processes such as storage, transport, packaging, etc. (Ormanc1, 2007). Such widely used polymer structured plastics, as a group, contain various types like polyvinyl chloride (PVC), polytetrafluoroethylene (PTFE), polypropylene (PP), polyethylene (PE), polyethylene terephthalate (PET) (Akkurt, 1991). PVC is very cost efficient and used frequently in plastic industry (Marcilla et al., 2008). Polyvinylchloride is transparent and shockproof, when burned the chlorine atoms are freed and they act as an inhibitive shield against fire, $1.35-1.45 \mathrm{~g} / \mathrm{cm}^{3}$ vinyl chlorine monomer polymerized in pressure tanks forms this polymer product (Kirwan \& Strawbridge, 2003). In order to gain flexibility high quantity of plasticisers (softeners) are added into Polyvinylchloride which usually has a rigid formation (Durusoy \& Karababa, 2011). For commercial purposes the most commonly used plasticiser is the phthalates. They move in between PVC molecules and sustain the space between the polymer molecules in order to add

1 | $\mathrm{P}$ a g e

www.iiste.org 
flexibility to Polyvinylchloride (Yerlikaya, 2017). As well as flexibility, malleability and strength can also be obtained by the addition of phthalate into plastics, and all these make PVC a very popular product all around the world, however almost half of the PVC products are made up of phthalates (Yaman Artunç, 2020).

\section{Phthalates}

Phthalate acid esters (benzene 1,2- dicarboxylic acid), commercially the most preferred plasticizers, known as phthalates, are produced with long chain alcohols esterifying with phthalic anhydride (Cadogan, 2002). Their chemical structure is shown in Fig.1 (Hauser \& Calafat, 2005). Phthalates are colourless, odourless and are liquids in room temperature (Guo et al., 2011). It has lipophilic structure and therefore has less water solubility, and more fat-solubility (Lyche et al., 2009). Due to its fatsolubility, when they get in touch with fatty foods or foods that are preserved in fat there is a risk of leakage from the plastic (Yerlikaya, 2017).<smiles>CCOC(=O)c1ccccc1C(=O)OCC</smiles>

Figure 1. General chemical structure of phthalates (Hauser \& Calafat, 2005)

Phthalates are the most preferred among the plasticizer materials that are popular throughout the world; and more than 25 types of phthalates are utilized. Ranked in order of preference of use, the first 10 phthalates are; di-(2-ethylhekzyl) phthalate (DEHP), dibutyl phthalate (DBP), dimethyl phthalate (DMP), diethyl phthalate (DEP), Di isobutyl phthalate (DiBP), butyl benzyl phthalate (BBzP), disiklohekzyl phthalate (DCHP), di-n-octyl phthalate (DnOP), di-isononyl phthalate (DiNP) and diiodosyl phthalate (DiDP) (Yaman Artunç, 2020). Updated list for frequency and uses are shown in Table: 1 (Erkekoğlu, 2009).

Phthalates branch in two categories according to their weight as heavy molecular weight phthalates and low molecular weight phthalates. Heavy molecular weight phthalates are DEHP, BBzP, DiNP, DnOP ve DiDP, and these phthalates show less cumulation in organisms. Low molecular weight plasticizer materials like DBP, DEP, DiBP cumulate more in living organisms are more resistant to heat and are more dissolvable in water (Mariana et al., 2016). Heavy molecular weight phthalates are preferred in construction materials, clothing and food packaging (Lyche et al., 2009) and low molecular phthalates are preferred in solvent material production, makeup materials and in drug development (Heudorf et al., 2007). In every areal of daily life we are confronted with these materials which are affecting human and animal health negatively as proven by numerous tests and research results. Research results show that specially DEHP, which is used widely because it increases the products flexibility and resistance, is the most harmful for the environment and its use was legally restricted (Wang et al., 2019; Yerlikaya, 2017).<smiles>CCCCC(CC)COC(=O)c1ccccc1C(=O)OCC(CC)CCCC</smiles>

Figure 2. DEHP (Di-(2-etilhekzil) phthalate) (NTP-CERHR, 2006)

2 | P a g e 
Table 1. Some Phthalates and their use (Erkekoğlu, 2009)

\begin{tabular}{|c|c|c|}
\hline Phthalate & Abbreviation & Use in \\
\hline Dimethyl phthalate & DMP & Repellent, plasticizer \\
\hline Diethyl phthalate & DEP & $\begin{array}{l}\text { Cosmetics, solvents, medicine } \\
\text { capsules, capsule production) }\end{array}$ \\
\hline Dibutyl phthalate & DBP & $\begin{array}{l}\text { Adhesives, Cosmetics, solvents, } \\
\text { medicines (tablet covering, } \\
\text { capsule production) }\end{array}$ \\
\hline Di isobutyl phthalate & DIBP & Adhesives, Cosmetics, solvents, \\
\hline Butyl benzyl phthalate & BBP & $\begin{array}{l}\text { Vinyl, floor covering, adhesives, } \\
\text { solvents, stamp production, } \\
\text { rubber and polymer productions, } \\
\text { stabilator, }\end{array}$ \\
\hline Di cyclohexylamine phthalate & DCHP & \\
\hline Di (2- ethylhexyl) phthalate & DEHP & $\begin{array}{l}\text { Plasticizer, (serum bags), toys, } \\
\text { household goods, food } \\
\text { packaging, paper industry, } \\
\text { electric condenser, } \\
\text { dyes/pigments, resin, rubber } \\
\text { industry, textile products }\end{array}$ \\
\hline Dioctyl phthalate & DOP & Plasticizer \\
\hline Diisononyl phthalate & DINP & Plasticizer, instead of DEHP use \\
\hline
\end{tabular}

Phthalates, as mentioned before, do not connect to the materials they combine with covalent bonds thus they may pass into the living body through the respiratory system, through cutaneous absorption from the skin or by blood circulation (intravenous exposure) all of which are important factors in their restriction (Sathyanarayana, 2008). In organisms phthalates are absorbed by the epithelial cells in the alimentary canal/digestive tract rather fast and their metabolism is also fast, however after absorption the metabolites that are formed are observed to be more toxic (National Research Council, 2009). Taken through oral route DEHP; can be degratated by pancreatic lipases in the small bowel and transforming into MEHP (monoethyl hexyl phthalate) or 2-ethylhexanol phthalate and then can be absorbed into the system. In animal researches it is ascertained that absorption can vary according to the species and with young animals intestine absorptions are more common than adults (Durmaz \& Özmert, 2010). Phthalates do not have acute toxicity and studies on chronic effects are obtained only from experimental animals (Erkekoğlu, 2009).

\section{Metabolic Effects of Phthalates}

Phthalates; can change the main systems regularities, like growth, development, metabolism, electrolyte balance, fertility in individuals or future generations and cause undesirable effects (Fendoğlu et al., 2019). At the start of these toxic effects, it is possible to observe oxidative stress, genotoxic effects and sensitivity to endogeny hormones. Exposure to plasticizers increases the reactive oxygen species (ROT) which causes DNA damage as well as metabolism of protein and lipid may be effected (Swedenborg et al., 2009). Özkemahlı (2018) in his study have evaluated the balance of oxidant and antioxidant plasticizers in the liver of human liver cells (HepG2). From antioxidant enzymes the superoxide dismutase, glutathione peroxidase, catalase showed a meaningful increase

3 | $\mathrm{P}$ a g e

www.iiste.org 
statistically, in ROT and MDA malondialdehyde (important indicator of lipid peroxidation) again increase was observed but in comparison to the control group only. Another study is, after the ethical death of pregnant rats the sterilized cell cultures obtained from their uterus was exposed to fibric derivatives for 96 hours. During embryonic development it was observed how arms and legs were developed like bud cells. The result showed that concentration of phthalate derivatives and toxic effects were positively correlated and increasing and cell developments were inhibited. According to the results in this study, it was considered that the contracture in extremity cells being inhibited were due to oxidative stress factor (Kim et al., 2002). In another study on vein endothelial cells, according to the phthalate derivative doze, increase of ROT level and cell destruction is located (Liu et al., 2017). Karaman (2020); in lung cancer cell cultures (A549); of one of the phthalate types, dibutyl phthalate, ROT production was more in comparison to the control group; and increase of protein carbonyl level was observed, which is an indicator of or MDA levels and protein oxidation.

\section{Animal Studies}

Effects produced by phthalates intruding easily into living things are confirmed by a lot of studies (Terzi, 2016; Yıldıztekin et al., 2017). Using phthalates so widely, risks the health of human, domestic animals and wildlife (Lyche et al., 2009). The tests made on laboratory animals shows and are proves how much phthalates are the cause of fatal deaths, malformations, liver damages, renal damages, hormonal disorders, infertility and most importantly toxic effects on breeding systems (Latini et al., 2006). Moreover, DEHP, a phthalate ester, which has been proved by National Toxology Programme, to be canceration on liver and DINP to be canceration on kidneys and liver (Shelby, 2006). Virtanen (2005), observed phthalates to be a threat on growth for both genders; also tests made on lab rats showed, to be exposed to high dose DBP results undescended testis syndrome. Researches results indicate that most important symptoms of the phthalates are decreases in the testosterone levels and the number of testis Leyding cells and that the most responsive species to testicular toxics effects among test animals are the rats (Karabulut, 2014). Phthalates like DEHP or DBP, when injected intracisternal in specific dozes to young male rats, it is observed that motor activity in brain development is accelerated (Mosuo et al., 2004). Testis legions in mature rats are at low levels, in young rats testis legions show high symptoms (Erkekoğlu, 2009). Erkekoğlu (2009) stated in his study; in rats, selenium support has shown to be a protective barrier for hormonal effects and in species having selenium deficiency antioxidant/oxidant balance is changed in favour of oxidant. In another study Karabulut (2014), has implemented male rats DEHP by gavage for 28 days, and reached the results of DNA damage, moreover weight increase in liver due to peroxisome proliferation and kidney degeneration was also observed. Study assessments on Phthalate effects on female reproductive systems, when pregnant rats are exposure to DEHP increase in primer follicle quantity is observed (Nierman et al., 2015), in another study when female sheep exposure to DEHP, ovulation problems, changes in corpus lutumun formations as well as ovary expansions, ovary evolution in females and decrease of luteinize hormones which is vital for testis activity in male sheep are determined (Herreros et al., 2013). Phthalates, also effects the ensülin metabolisms negatively. Pregnant rats, if they are exposure to DEHP by gavage, between 9 th to 21 st days of pregnancy, as a result it is observed that youngs show hyperglycaemia, impaired glucose tolerance and pancreatic ensülin decrease problems (Rajesh \& Balasubramanian, 2015). In another study, in low doses, DEHP supresses aromatase enzyme which is responsible to transform testosterone into oestradiol, but on the other hand highly stimulate it with high does. Thus, it is ascertained that, aromatase enzyme increase in presence of DEHP causes testosterone level decrease, therefore sperm reproduction also decreases (Durmaz \& Özmert, 2010). Along with empiric emal studies, highest risk from exposure to plasticizers naturally are for aquatic organisms as water reserves such as rivers, lakes are under threat of plastic material waste pollution and biological balance is getting lost in nature (Şişman, 2007).

Phthalates can dissolve in fat and this is the reason why plasticizers are at minimum levels in low fat fish (Mozstudyaffarian et al., 2006). In his study on Zebra fish, Terzi (2016) found that when exposed to plasticizers depending on concentration level, there was low level increase in DNA damages and because of metabolism damage and immune system suppress origination of important changes in outer view has been detected. Another study in zebra fish proved that plasticizers cause zygogenesis process slow down, space around the heart narrows, blood stream decreases, hatching larva quantity lessens, congenital anomalies due to fatal development and deaths can occur (Şişman, 2007).

4 | $\mathrm{P}$ a g e 


\section{Results}

Major factor for every living thing is to maintain a healthy life. In Turkey; unplanned random urbanization, industrial complexes discharging waste directly to surrounding without effluent treatment plant and using noxious materials without caution results unbalanced biological environment with growing contamination. As a result of industrial production, generated solid waste and polluted waters melt into lakes, rivers and seas which means it is inevitable that plasticizers and its derivatives, sharing the same industrial system, will be melting into all our clean waters as well. Industrial development causes living organisms getting in touch with chemical materials more and more every year and therefore effects are also getting more. Among these chemical materials phthalates are important; their use was meant to easy the life of living and for this easy to use products were designed, but controversially they became one of the biggest risks for the lives of many species. Where rigid plastics could not be forced to take a desired shape or form, Phthalates converts this rigid plastic to be an adequate material usable as desired and make it convenient for production. However, besides these valuable characteristics, plasticizers, have a strong composition against decomposition, they become intracellular deposits and may cause toxicity in the body. In the body of living, phthalates may cause symptoms which can be effective on many systems but they can also cause health problems which may be very hard to reclaim back. People purchasing all kinds of products do not take into consideration of the packaging materials which contains phthalate in them. Therefore, even though people are exposed to phthalate and phthalate esters so much, they actually support the producers to produce more because of the consumption density people are causing themselves. Due to production growth, the waste also grows and because of their strong decomposition characteristic, they cumulate in the environment and pollute natural resources and health of animals living in nature are also affected negatively.

As a result; it is important that widely used phthalates should be under regular control according to their legal restriction limits, their consumption quantities should be followed and it should be abstained to use plastic cups and packaging just for the sake of consuming. To conserve public health as well as natural resources and animal habitats to exist in their natural selection it is important to be aware of exposure to phthalates.

\section{References}

Akkurt S. (1991). “Plastic Material Information”, Birsen Publishing House, 7, İstanbul.

Cadogan, D. (2002). Health and environmental impact of phthalates. Plastics, Additives and Compounding, 4(6), 28-29.

Durmaz, E., \& Özmert, E. N. (2010). Phthalates and child health., Journal of Child Health and Diseases, 53(4).

Durusoy, R., \& Karababa, A. O. (2011). Plastic food packaging and health. TAF Preventive Medicine Bulletin, 10(1).

Erkekoğlu Ü. P. (2009). Evaluation of reproductive toxicity of di-2-(ethylhexyl) phthalate in selenium-deficient and selenium-supplemented rats. Hacettepe University Institute of Health Sciences Pharmaceutical Toxicology Program (PhD Thesis, Ankara).

Fendoğlu, B. Y., Koçer-Gümüşel, B., \& Erkekoğlu, P. (2019). An Overview of Endocrine Destructive Chemicals and Mechanisms of Action. Hacettepe University Faculty of Pharmacy Journal, 39(1), 30-43.

Guo, Y., Wu, Q., \& Kannan, K. (2011). Phthalate metabolites in urine from China, and implications for human exposures. Environment international, 37(5), 893-898.

Hauser, R., \& Calafat, A. M. (2005). Phthalates and human health. Occupational and environmental medicine, 62(11), 806-818.

5 | P a g e

www.iiste.org 
Herreros, M. A., Encinas, T., Torres-Rovira, L., Garcia-Fernandez, R. A., Flores, J. M., Ros, J. M., \& Gonzalez-Bulnes, A. (2013). Exposure to the endocrine disruptor di (2-ethylhexyl) phthalate affects female reproductive features by altering pulsatile LH secretion. Environmental Toxicology and Pharmacology, 36(3), 1141-1149.

Heudorf, U., Mersch-Sundermann, V., \& Angerer, J. (2007). Phthalates: toxicology and exposure. International journal of hygiene and environmental health, 210(5), 623-634.

Hüner, Ü. (2008). Investigation of Hot Joining Processes of Plastic Based Composite Materials. Trakya University, Institute of Science and Technology, Department of Mechanical Engineering (PhD Thesis, Master's Thesis, Edirne).

Karabulut, G. (2014). Investigation of the Genotoxic, Histological and Biochemical Effects of Di(2Ethylhexyl) Phthalate in Pubertal Male Rats.

Karaman, G. (2020). Evaluation of Toxic Effects of Dibutyl Phthalate on Human Lung Cell Line and Possible Protective Effects of Ascorbic Acid and N-Acetylcysteine.

Kim, S. H., Kim, S. S., Kwon, O., Sohn, K. H., Kwack, S. J., Choi, Y. W., ... \& Park, K. L. (2002). Effects of dibutyl phthalate and monobutyl phthalate on cytotoxicity and differentiation in cultured rat embryonic limb bud cells; protection by antioxidants. Journal of Toxicology and Environmental Health Part A, 65(5-6), 461-472.

Kirwan, M. J., \& Strawbridge, J. W. (2003). Plastics in food packaging. Food packaging technology, 1, 174-240.

Latini, G., Del Vecchio, A., Massaro, M., Verrotti, A., \& De Felice, C. (2006). In utero exposure to phthalates and fetal development. Current medicinal chemistry, 13(21), 2527-2534.

Liu, N., Jiang, L., Sun, X., Yao, X., Zhai, X., Liu, X., ... \& Yang, G. (2017). Mono-(2-ethylhexyl) phthalate induced ROS-dependent autophagic cell death in human vascular endothelial cells. Toxicology in Vitro, 44, 49-56.

Lyche, J. L., Gutleb, A. C., Bergman, Å., Eriksen, G. S., Murk, A. J., Ropstad, E., ... \& Skaare, J. U. (2009). Reproductive and developmental toxicity of phthalates. Journal of Toxicology and Environmental Health, Part B, 12(4), 225-249.

Marcilla, A., García, S., \& Garcia-Quesada, J. C. (2008). Migrability of PVC plasticizers. Polymer Testing, 27(2), 221-233.

Mariana, M., Feiteiro, J., Verde, I., \& Cairrao, E. (2016). The effects of phthalates in the cardiovascular and reproductive systems: A review. Environment international, 94, 758-776.

Masuo, Y., Morita, M., Oka, S., \& Ishido, M. (2004). Motor hyperactivity caused by a deficit in dopaminergic neurons and the effects of endocrine disruptors: a study inspired by the physiological roles of PACAP in the brain. Regulatory peptides, 123(1-3), 225-234.

Mozaffarian, D., \& Rimm, E. B. (2006). Fish intake, contaminants, and human health: evaluating the risks and the benefits. Jama, 296(15), 1885-1899.

National Toxicology Program. (2006). NTP CERHR Monograph on the Potential Human Reproductive and Developmental Effects of Di(2-ethhylhexyl) Phthalate (DEHP).

National Research Council. (2009). Phthalates and cumulative risk assessment: the tasks ahead. 
Niermann, S., Rattan, S., Brehm, E., \& Flaws, J. A. (2015). Prenatal exposure to di-(2-ethylhexyl) phthalate (DEHP) affects reproductive outcomes in female mice. Reproductive Toxicology, 53, 23-32.

Ormanc1, F. S. B. (2007). Use of PVC material in packaging of dairy products and migration. Food, 32(4), 187-193.

Özkemahlı, K. G. (2018). Evaluation of the Effects of Combined Exposure to Endocrine Destructive Chemicals in the Hepg2 Cell Line.

Rajesh, P., \& Balasubramanian, K. (2015). Gestational exposure to di (2-ethylhexyl) phthalate (DEHP) impairs pancreatic $\beta$-cell function in F1 rat offspring. Toxicology letters, 232(1), 46-57.

Sathyanarayana, S. (2008). Phthalates and children's health. Current problems in pediatric and adolescent health care, 38(2), 34-49.

Shelby, M. D. (2006). NTP-CERHR monograph on the potential human reproductive and developmental effects of di (2-ethylhexyl) phthalate (DEHP). Ntp Cerhr Mon, (18), v-vii.

Swedenborg, E., Rüegg, J., Mäkelä, S., \& Pongratz, I. (2009). Endocrine disruptive chemicals: mechanisms of action and involvement in metabolic disorders. Journal of molecular endocrinology, 43(1), 1-10.

Şişman, T. (2007). Effects of Polychlorinated Biphenyl Compounds on Danio rerio (Zebrafish) Development. Ataturk University Institute of Science and Technology. Graduate School of Natural and Applied Sciences. Department of Biology, PhD Thesis, Erzurum.

Terzi, S. (2016). Toxic effects of dioctyl adipate and dioctyl phthalate, which are used as plasticizers in industry, on zebrafish larvae (Master's thesis, Recep Tayyip Erdoğan University/Institute of Science/Department of Fisheries Basic Sciences).

Virtanen, H. E., Rajpert-De Meyts, E., Main, K. M., Skakkebaek, N. E., \& Toppari, J. (2005). Testicular dysgenesis syndrome and the development and occurrence of male reproductive disorders. Toxicology and applied pharmacology, 207(2), 501-505.

Vural, N. (1977). Toxicological assessment of plastic food containers used in Turkey. Journal of Ankara University Faculty of Pharmacy, 7(2).

Wang, Y., Zhu, H., \& Kannan, K. (2019). A review of biomonitoring of phthalate exposures. Toxics, 7(2), 21.

Yaman Artunç, N. (2020). Examınatıon Of The Relatıonshıp Between Speech Delay And Plasma Phthalate Level In Children.

Yerlikaya, P. (2017). Phthalate esters and their place in seafood consumption. Food and Health, $3(2), 59-66$.

Yildiztekin, K. G., Erkekoğlu, P., \& Koçer-Gümüşel, B. (2017). Are Plastics a Health Threat? An Overview of Phthalates. FABAD Journal of Pharmaceutical Sciences, 42(2), 111. 